\title{
The Global Energy Balance Archive (GEBA) version 2017: a database for worldwide measured surface energy fluxes
}

\author{
Martin Wild ${ }^{1}$, Atsumu Ohmura ${ }^{1}$, Christoph Schär ${ }^{1}$, Guido Müller $^{1}$, Doris Folini ${ }^{1}$, Matthias Schwarz ${ }^{1}$, \\ Maria Zyta Hakuba ${ }^{2,3}$, and Arturo Sanchez-Lorenzo ${ }^{4}$ \\ ${ }^{1}$ Institute for Atmospheric and Climate Science, ETH Zurich, 8092 Zurich, Switzerland \\ ${ }^{2}$ Department of Atmospheric Sciences, Colorado State University, Fort Collins, CO 80523, USA \\ ${ }^{3}$ NASA Jet Propulsion Laboratory, California Institute of Technology, Pasadena, CA 91109, USA \\ ${ }^{4}$ Pyrenean Institute of Ecology (IPE), Spanish National Research Council, Zaragoza, Spain
}

Correspondence to: Martin Wild (martin.wild@env.ethz.ch)

Received: 7 April 2017 - Discussion started: 2 May 2017

Revised: 19 July 2017 - Accepted: 20 July 2017 - Published: 23 August 2017

\begin{abstract}
The Global Energy Balance Archive (GEBA) is a database for the central storage of the worldwide measured energy fluxes at the Earth's surface, maintained at ETH Zurich (Switzerland). This paper documents the status of the GEBA version 2017 dataset, presents the new web interface and user access, and reviews the scientific impact that GEBA data had in various applications. GEBA has continuously been expanded and updated and contains in its 2017 version around 500000 monthly mean entries of various surface energy balance components measured at 2500 locations. The database contains observations from 15 surface energy flux components, with the most widely measured quantity available in GEBA being the shortwave radiation incident at the Earth's surface (global radiation). Many of the historic records extend over several decades. GEBA contains monthly data from a variety of sources, namely from the World Radiation Data Centre (WRDC) in St. Petersburg, from national weather services, from different research networks (BSRN, ARM, SURFRAD), from peer-reviewed publications, project and data reports, and from personal communications. Quality checks are applied to test for gross errors in the dataset. GEBA has played a key role in various research applications, such as in the quantification of the global energy balance, in the discussion of the anomalous atmospheric shortwave absorption, and in the detection of multi-decadal variations in global radiation, known as "global dimming" and "brightening". GEBA is further extensively used for the evaluation of climate models and satellite-derived surface flux products. On a more applied level, GEBA provides the basis for engineering applications in the context of solar power generation, water management, agricultural production and tourism. GEBA is publicly accessible through the internet via http://www.geba.ethz.ch. Supplementary data are available at https://doi.org/10.1594/PANGAEA.873078.
\end{abstract}

1

Knowledge on the spatiotemporal distribution of the individual energy balance components at the Earth's surface is essential for the understanding of the genesis and evolution of Earth's climate. Such knowledge is also required for various practical applications in the sectors of renewable energy, agriculture, water management, and tourism. Surface energy fluxes are not directly measurable from space, as the associated signals reaching the satellite sensors are significantly perturbed on their transfer through the atmosphere. Correction of these atmospheric influences therefore requires the use of models or empirical relations, which induces uncertainties. Therefore, direct measurements taken at the Earth's surface are essential as an independent information source for the quantification of the surface energy fluxes. The monitoring of some of the surface energy fluxes, particularly shortwave radiation incident at the Earth's sur- 
face, started in the early 20th century at a small number of sites. More widespread measurements of the surface energy balance components were initiated in the International Geophysical Year (IGY, 1957/1958). Many of these historic measurements have been compiled in the Global Energy Balance Archive (GEBA) at ETH Zurich, whose 2017 version is described in the following.

\section{History of GEBA}

In the early 1980s, Atsumu Ohmura and collaborators at ETH Zurich started to systematically collect data from any accessible source on directly measured monthly mean energy balance components at the Earth's surface around the world. These sources included data from monographs, periodicals, data reports, personal communications, and published and unpublished manuscripts, which were initially stored on paper forms. In 1985, the data compilation included about 5000 energy flux values in such paper records. In 1986, this endeavor became a project of the World Climate Program-Water. To transfer the data collection into digital form, a database approach was chosen. The first version of the GEBA database was implemented in 1988, following the design of a relational database (Ohmura et al., 1989). In April 1991, the GEBA database was opened to the scientific community for the first time. In the subsequent years, GEBA has been steadily growing, as documented in reports on early versions of GEBA (Ohmura and Gilgen, 1991; Gilgen et al., 1997; Gilgen and Ohmura, 1999). In GEBA version 1991, all flux data, collected in different units, were converted into the common unit watts per square meter $\left(\mathrm{W} \mathrm{m}^{-2}\right)$ before storage. To facilitate the quality assessments and traceability of the data, in GEBA version 1995 an additional internal table was implemented in the relational database, which also contains the data in their original units. In October 1997, GEBA became accessible through the internet for the first time. Since the retirement of Professor Ohmura in 2007, the first author of this paper has ensured the continuation of GEBA at ETH Zurich. The continuation of GEBA became possible through the technical support and maintenance of the database by the IT services of ETH Zurich from 2008 onward, which also included a complete renewal of the technical infrastructure.

As compared to the early documentations of GEBA in the 1990s, GEBA has undergone substantial changes in terms of available data, data access, and internet appearance and has played a key role in major research activities, as outlined in the sections below.

\section{Content and data sources of GEBA}

GEBA compiles monthly mean data from various energy fluxes observed at the Earth's surface, namely global radiation (i.e., total surface downward shortwave radiation, also known as surface solar radiation), diffuse and direct short- wave radiation, surface albedo and reflected shortwave radiation, longwave downward and upward radiation, radiation balance (surface net radiation), sensible and latent heat flux, subsurface heat flux, and latent heat of melt (see Table 1). GEBA contains strictly only directly measured surface energy fluxes; empirically derived fluxes are not considered.

Over the years, monthly mean surface energy flux data have been compiled from various sources, namely from the World Radiation Data Center (WRDC) in St. Petersburg, from the Baseline Surface Radiation Network (BSRN) (Ohmura et al., 1998), from the Atmospheric Radiation Measurement program (ARM) (Stokes and Schwartz, 1994), from the surface radiation (SURFRAD) network maintained by NOAA (Augustine et al., 2000), from various periodicals, journal publications, and data reports, from personal communications of unpublished data, and from individual weather services such as MeteoSwiss. In addition, researchers and institutions are encouraged to make their surface energy flux data widely available through GEBA. Please contact the first author if you are willing to contribute your data.

GEBA in its 2017 version contains data from 2500 worldwide distributed locations as shown in Fig. 1 (yellow and red symbols), with about 500000 monthly mean values (Table 1). From 1155 of these locations multiyear records with at least 3 years of data are available (yellow symbols in Fig. 1). By far the largest number of data in GEBA refer to the surface downward shortwave radiation (Table 1).

Error estimates of these data and the quality checks applied are described in detail in Gilgen et al. (1998) and Gilgen and Ohmura (1999). All energy fluxes stored in the GEBA database are subject to a "physical sanity" check, which requires the energy flux values to be within physically possible magnitudes (Gilgen and Ohmura, 1999). Since GEBA compiles data measured by the entire community as far back in time as possible and consists of heterogeneous data sources, their accuracy is inevitably variable. Most of the shortwave radiation measurements in GEBA were made with pyranometers. These measurements have instantaneous accuracy limitations of 3-5\% of the full signal due to cosine response and thermal offset errors combined with other sources of uncertainty (Michalsky et al., 1999; Wild et al., 2013). Their accuracy in the field in terms of relative random measurement error has been estimated by Gilgen et al. (1998) at $5 \%$ of the monthly mean and $2 \%$ of the yearly mean values, based on comparisons of long-term pyranometer measurements from five pairs of nearby stations stored in GEBA. Diffuse shortwave radiation measurements are obtained by shading the pyranometers from the direct solar beam, with an instantaneous accuracy of $2-4 \mathrm{~W} \mathrm{~m}^{-2}$ under ideal conditions (Michalsky et al., 2007). The instantaneous accuracy of downward longwave radiation measurements carried out with pyrgeometers is near $3-4 \mathrm{~W} \mathrm{~m}^{-2}$ under ideal conditions (Philipona et al., 2001; Marty et al., 2003; Wang and Dickinson, 2013b). No assessments of the accuracy of the nonradiative fluxes on monthly timescales as stored in GEBA 
Table 1. List of the various energy balance components included in GEBA, with the number of sites measuring each component, the number of monthly values included, and the earliest year that has data for each component in GEBA.

\begin{tabular}{lrrr}
\hline Energy balance component & \#Sites & \#Monthly means & First year measured \\
\hline Global (downward shortwave) radiation & 2249 & 357583 & 1919 \\
Direct shortwave radiation & 109 & 9553 & 1934 \\
Diffuse shortwave radiation & 787 & 70069 & 1950 \\
Albedo & 510 & 3839 & 1954 \\
Reflected shortwave radiation & 97 & 5827 & 1954 \\
Longwave incoming radiation & 83 & 3984 & 1954 \\
Longwave outgoing radiation & 48 & 1659 & 1954 \\
Longwave net radiation & 30 & 735 & 1959 \\
Radiation balance & 709 & 25392 & 1954 \\
Sensible heat flux & 62 & 250 & 1980 \\
Latent heat flux & 75 & 686 & 1980 \\
Subsurface heat flux & 61 & 481 & 1968 \\
Latent heat of melt & 20 & 59 & non-permanent \\
Ultraviolet radiation & 10 & 242 & 1976 \\
Other components & 81 & 26814 & 1957 \\
Absorbed global radiation & 32 & 1609 & 1947 \\
Outgoing short + longwave radiation & 2 & 24 & 1959 \\
Sum of latent and sensible heat flux & 2 & 21 & 1976 \\
Circumglobal radiation & 4 & 501 & 1958 \\
\hline
\end{tabular}

are available. While the random errors of these components largely reduce on monthly timescales compared to instantaneous measurements, studies suggest an overall systematic error inferred from the non-closure of the energy balance on the order of 11-21\% (Franssen et al., 2010 and references therein).

The longest record in GEBA comes from Stockholm and contains downward shortwave radiation observations exceeding 90 years back to 1922 (Fig. 2). With its focus on monthly data, the GEBA dataset is designed for climatological applications. For energy flux data with higher temporal resolution, the reader is referred to other sources such as the database of the BSRN (http://bsrn.awi.de/), which provides surface radiation data at minute resolution. GEBA is currently an unfunded project. Therefore, the update frequency of the data records (if available) may be irregular depending on the available resources at the host institute.

\section{Access to GEBA}

GEBA is accessible worldwide through the internet. The official URL address of GEBA version 2017 is www.geba.ethz. ch. Note that the URL address published in older documentations is no longer valid. GEBA version 2017 comes with a newly designed user interface and user administration tool. To grant access to the data, a registration is required, which can be achieved by filling in the respective form provided on the GEBA website. Thereon, a specification of the intended usage of the data is also required. It is the policy of GEBA that the data are available at no cost for bona fide research. Direct commercial use, i.e., selling, of the data is not allowed.

The new user interface allows the selection of the various energy balance components stored in GEBA as given in Table 1 , as well as the period under consideration (Fig. 3 left). It then further allows the selection of specific regions, countries, or individual stations of interest (Fig. 3 center and right panels). Based on this information, a database query is generated to process the retrieval of the desired selection. The user in return obtains two different files, one file containing the original energy flux data and one file containing metadata in terms of station names, coordinates, station history with known changes in instrumentation, data evaluation procedures, and data publication standards. The specification of the data formats of the two files can be found on the GEBA website in the "Data Formats" section under the "Data Retrieval" menu. As mentioned previously, GEBA internally stores all data in the original units as they were published, as well as converted into watts per square meter. All data retrieved by the users through the web-interface are, however, exclusively in watts per square meter, to facilitate their usage and avoid misinterpretation.

\section{Research done with GEBA}

GEBA data have been applied in many studies and have contributed to a number of key scientific issues. In the following, we will review some of the achievements that have been obtained using GEBA data. 


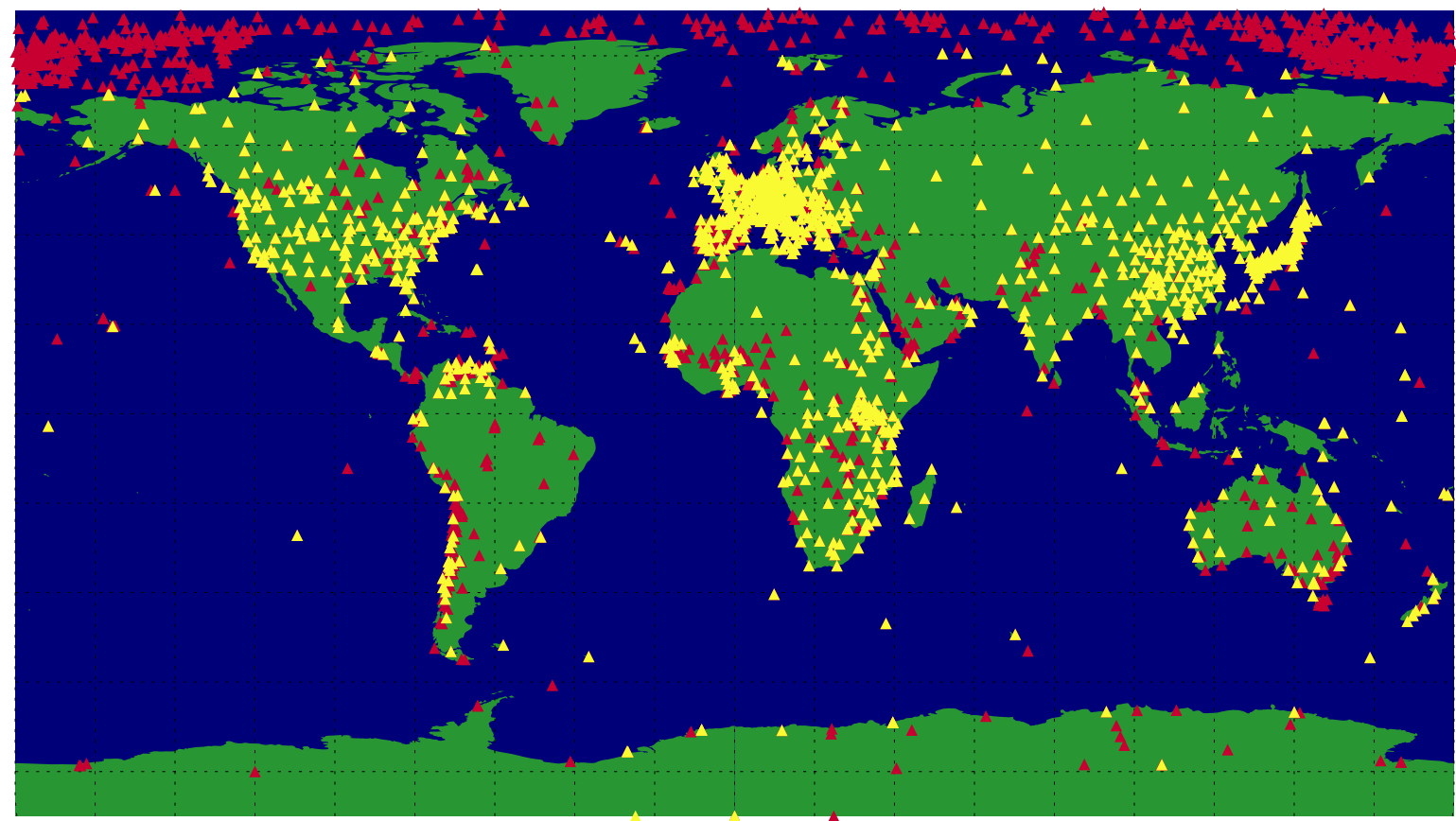

Figure 1. Distribution of the 2500 locations with observational data contained in GEBA. Red symbols indicate locations with at least one monthly entry in GEBA; yellow symbols signify locations with multiyear records (at least 3 years of data).

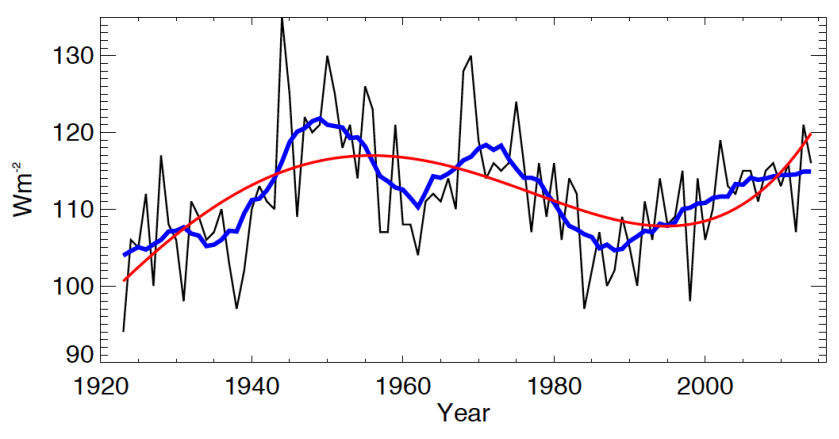

Figure 2. The longest continuous record available in GEBA: surface downward shortwave radiation $\left(\mathrm{W} \mathrm{m}^{-2}\right)$ measured in Stockholm since 1922. The blue line shows the 5-year moving average; the red line shows the fourth-order polynomial fit. Substantial multidecadal variations become evident, with an increase up to the $1950 \mathrm{~s}$ (early brightening), an overall decline from the 1950 s to the $1980 \mathrm{~s}$ (dimming), and a recovery thereafter (brightening).

\subsection{Estimation of the global energy balance}

A major aim of GEBA since its initiation in the 1980s was the reevaluation of the global energy balance (Ohmura et al., 1989). Particularly challenging is thereby the determination of the energy fluxes at the Earth's surface, which cannot be directly measured from space and which are accordingly afflicted with substantial uncertainties. Information from direct observations at the surface as provided by GEBA is therefore particularly valuable to constrain these fluxes. A first estimation of the geographical distribution of the individual surface energy balance components based on direct observations from GEBA was performed by Ohmura and Gilgen (1993) and updated in Ohmura and Raschke (2005). Wild et al. (1998b) used a combination of GEBA data and respective biases of a climate model to infer the magnitudes of the global mean energy balance components. For the Fifth Assessment Report of the Intergovernmental Panel on Climate Change (IPCC-AR5) they updated their global energy balance estimates using a similar methodology based on a comprehensive set of state of the art models from the Coupled Model Intercomparison Project Phase 5 (CMIP5) and their biases with respect to GEBA and BSRN stations (Wild et al., 2013, 2015) (Fig. 4). The methodology also allowed the estimation of the Earth's energy balance separately over land and oceans (Wild et al., 2015). All these evaluations have advocated a lower surface downward shortwave and higher downward longwave radiation than in some of the traditional estimates such as those used in the IPCC assessments up to the Fourth Assessment Report.

A particular aspect of the global energy balance, namely the quantification of the absorption of shortwave radiation in the atmosphere, has been an issue to which GEBA data have contributed significantly over decades. In the early days of GEBA, it was debated whether estimates of shortwave atmospheric absorption may be too low due to an underestimated absorption in clouds, a phenomenon known as anomalous cloud absorption. GEBA was of key importance in quantify- 
GEBA

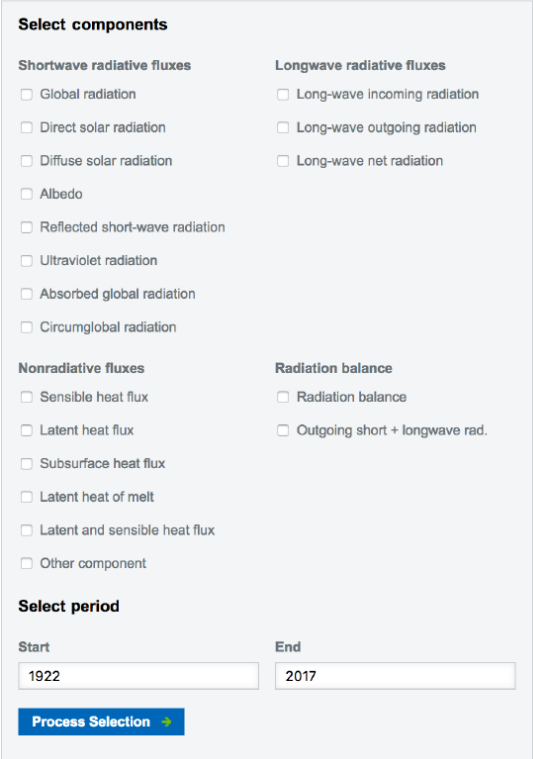

GEBA

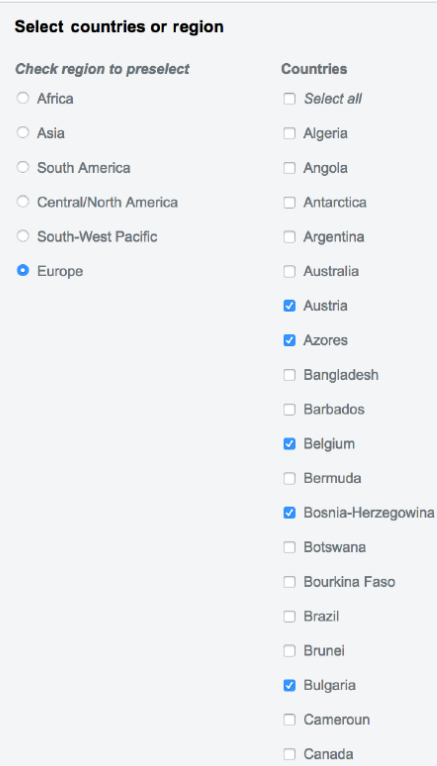

GEBA

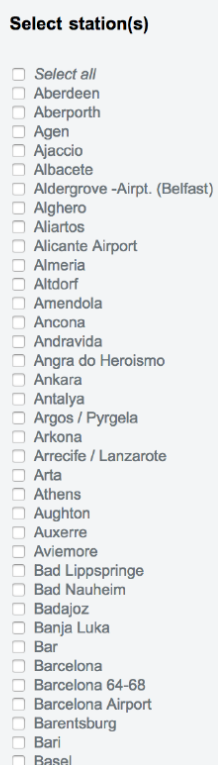

Figure 3. Example extract from the new GEBA web interface at www.geba.ethz.ch. The web interface allows the selection of a variety of surface energy balance components; the period to be retrieved; and the region, country, or specific stations of interest.

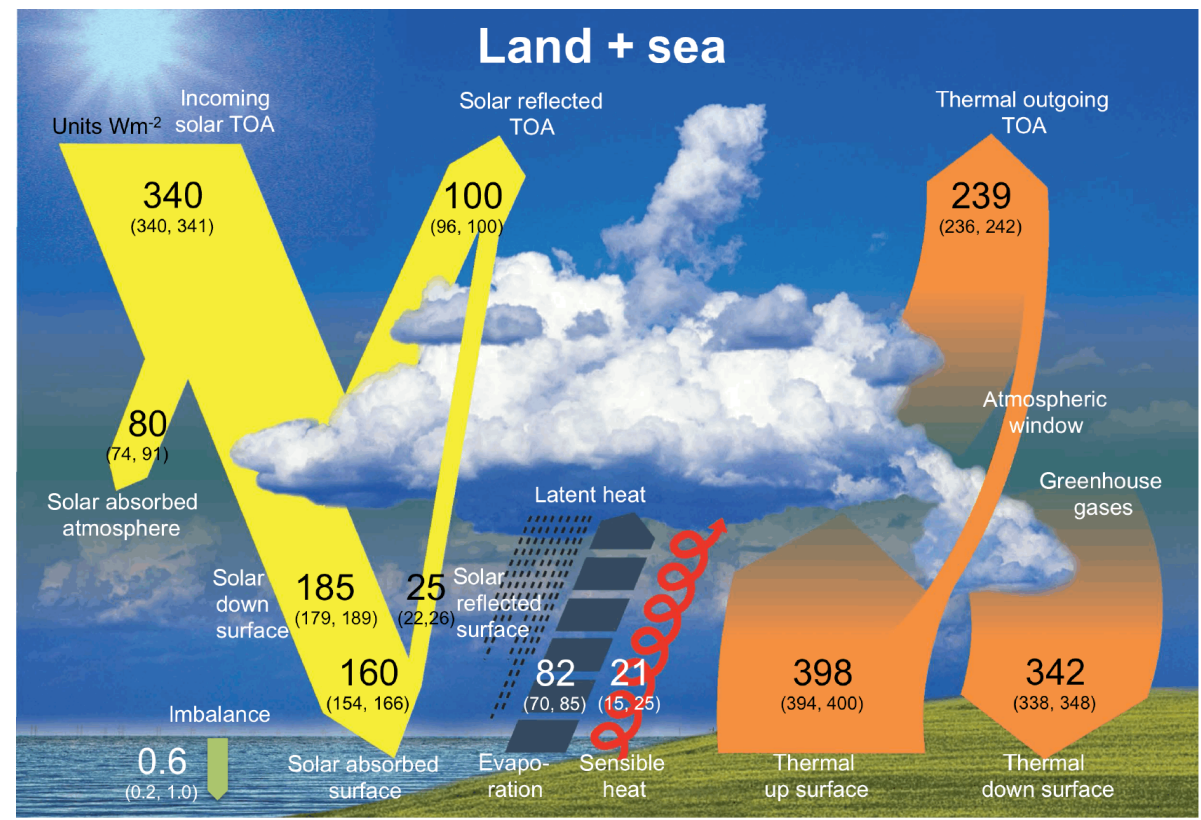

Figure 4. Schematic diagram of the global mean energy balance of the Earth. Numbers indicate best estimates for the magnitudes of the globally averaged energy balance components $\left(\mathrm{W} \mathrm{m}^{-2}\right)$ together with their uncertainty ranges in parentheses, representing present-day climate conditions at the beginning of the 21 st century. Top-of-atmosphere fluxes are determined from the CERES satellite observations. Surface radiative flux estimates are derived from the CMIP5 model bias structure with respect to GEBA and BSRN observations as outlined in Wild et al. (2013, 2015). Adapted from Wild et al. (2015). 


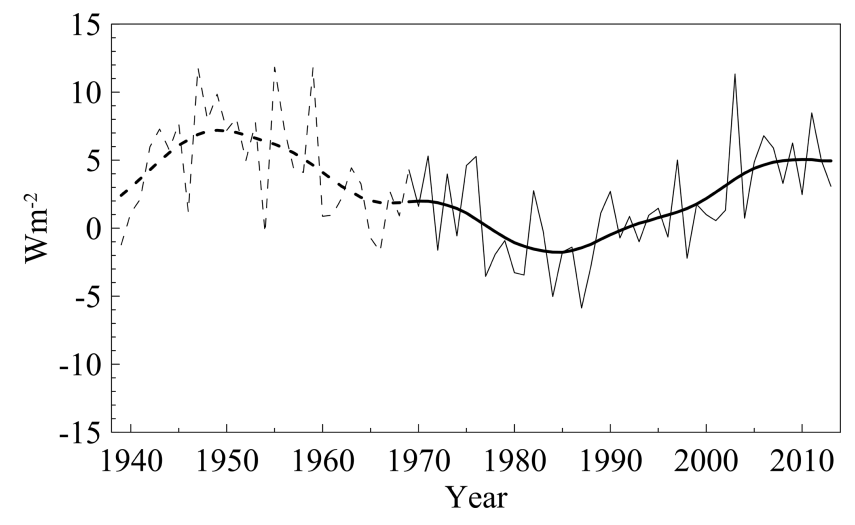

Figure 5. Composite of 56 European GEBA time series of annual surface downward shortwave radiation (thin line) from 1939 to 2013, plotted together with a 21-year Gaussian low-pass filter (thick line). The series are expressed as anomalies $\left(\mathrm{W} \mathrm{m}^{-2}\right)$ from the 1971-2000 mean. Dashed lines are used prior to 1961 due to the lower number of records for this initial period. Updated from Sanchez-Lorenzo et al. (2015) including data until December 2013.

ing the underestimation in atmospheric shortwave absorption and in relating it to a lack of absorption in the cloud-free atmosphere rather than in clouds (Li et al., 1995a; Wild et al., 1995). First attempts to estimate the shortwave atmospheric column absorption by combining surface observations from GEBA with collocated satellite observations of the top-ofatmosphere (TOA) fluxes from the Earth Radiation Budget Experiment (ERBE) were made in Wild et al. (1998b) and Wild (2000). More recently, with the advent of high-quality TOA satellite observations from the Clouds and the Earth's Radiant Energy System (CERES) program, CERES rather than ERBE data have been combined with GEBA data to improve the quantification of the atmospheric shortwave absorption (Hakuba et al., 2014b). To estimate potential uncertainties induced by the scale mismatch between the gridded $1^{\circ}$ TOA satellite data from CERES and the surface point observations from GEBA, the representativeness of the GEBA sites for their larger-scale surroundings has been thoroughly assessed (Hakuba et al., 2013, 2014a). Based on the collocated GEBA and CERES observations, the atmospheric shortwave absorption over Europe has been estimated by Hakuba et al. (2014b) at $23 \%$ of the TOA insolation. The $23 \%$ was shown to be largely invariant with respect to latitude and season (Hakuba et al., 2014b, 2016) and in line with recent global estimates (Wild et al., 2013, 2015). Globally it has been estimated that one-third of the absorption of shortwave radiation in the climate system takes place in the atmosphere and two-thirds takes place at the Earth's surface (Wild et al., 2015).

\subsection{Detection of decadal changes in the surface energy fluxes}

GEBA has played a key role in the discovery that the downward shortwave radiation at the Earth's surface has not been stable over the years, but instead underwent substantial multi-decadal variations (see Fig. 2 as an illustrative example). Based on European GEBA sites, Ohmura and Lang (1989) identified a downward trend in this component from the 1950s to the 1980s for the first time, a phenomenon that later became known as global dimming (Stanhill and Cohen, 2001). Follow-up studies found similar tendencies at GEBA sites around the world (e.g., Gilgen et al., 1998; Liepert, 2002; Wild, 2009 and references therein). When updating the GEBA records into the 2000s, Wild et al. (2005) noted a distinct trend reversal during the 1980s and widespread recovery from previous dimming, which they coined brightening (see Fig. 2). Chiacchio and Wild (2010) pointed out that the dimming and subsequent brightening at the European GEBA sites is particularly evident in spring and summer. The longest records in GEBA further indicate an increase in downward shortwave radiation in the 1930s and 1940s, which has been termed early brightening (Ohmura, 2006, 2009; Wild, 2009) (see Fig. 2).

Norris and Wild $(2007,2009)$ used the GEBA data and a satellite-derived regression method to estimate the effects of changes in cloud cover on dimming and brightening. Their results suggest that changes in cloud cover can hardly explain the observed decadal variations in surface shortwave radiation at European and Chinese sites, pointing to other important influential factors, particularly changes in aerosols and/or changes in cloud optical properties. However, the relative contribution of changes in aerosol and cloud characteristics (related or unrelated to aerosol changes) to the observed variations in downward shortwave radiation is still not well established at many sites, although conceptual frameworks exist (see e.g., Wild, 2012, 2016). It has also been controversially discussed to what extent the dimming and brightening trends in GEBA may have been subject to urbanization effects (Alpert et al., 2005; Wang et al., 2014; Imamovic et al., 2016).

A comprehensive assessment of the trends in Europe using homogeneous GEBA records is reported in Sanchez-Lorenzo et al. (2015). Figure 5 shows an updated composite mean series of the 56 European GEBA records used in SanchezLorenzo et al. (2015) and illustrates the sequence of early brightening, dimming, and brightening over Europe. A longterm diffuse radiation record from the station Toravere (Estonia) contained in GEBA is displayed in Fig. 6. The diffuse radiation shows opposite tendencies compared to Fig. 5, with an increase in the dimming period up to the mid-1980s, in line with enhanced scattering from aerosols and/or clouds in this period and a subsequent decrease in the brightening period with declining aerosol and/or cloud scattering. 


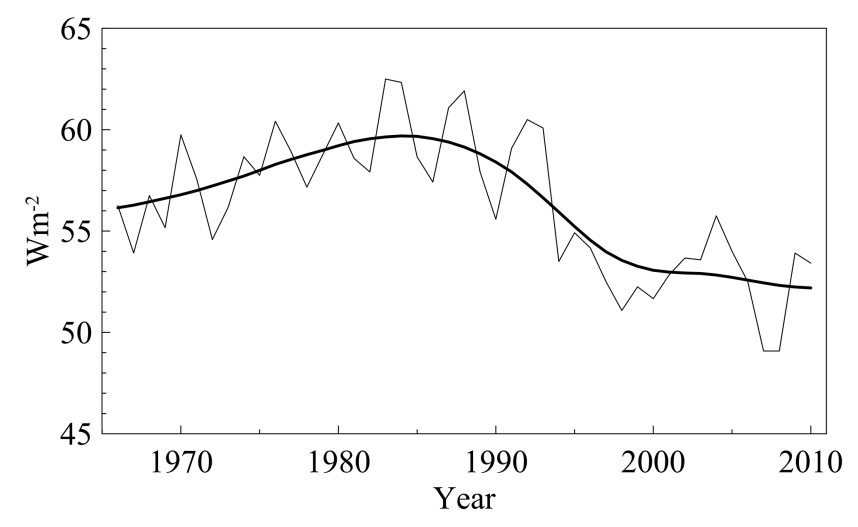

Figure 6. Long-term annual mean diffuse radiation $\left(\mathrm{W} \mathrm{m}^{-2}\right)$ record from 1966 to 2010 (thin line) plotted together with a 21year Gaussian low-pass filter (thick line) measured at the station Toravere (Estonia) contained in GEBA.

GEBA data have also been used to infer long-term trends in the nonradiative surface energy flux components, particularly latent heat (evapotranspiration). Ohmura and Lang (1989) noted that decadal changes in evapotranspiration run in parallel to the fluctuation in surface shortwave radiation. Wang et al. (2010) used shortwave radiation data from GEBA to reconstruct terrestrial evapotranspiration trends and showed that they undergo significant decadal variations.

\subsection{Validation of surface energy fluxes from climate models, reanalyses, and satellite products}

A major application of the GEBA dataset has always been its usage as ground truth and benchmark for the assessment of calculated gridded surface flux fields from climate models, satellite products, and reanalyses. GEBA data allowed the identification of major biases and weaknesses in these different products of surface energy flux estimates.

A first evaluation of the global surface radiation fields simulated by climate models with direct surface observations is documented in Wild et al. (1995), who revealed an overestimated downward shortwave radiation due to an overly transparent atmosphere in these models and an underestimated downward longwave radiation on a climatological mean basis. These biases turned out to be long-standing issues in many climate models up to the present day. Numerous assessments as reviewed in Wild (2008) underline the importance of GEBA as a primary reference dataset for radiative flux evaluation in global and regional climate models. GEBA-based evaluations of the radiation climatologies of the latest generation of climate models (CMIP5) used in IPCC-AR5 have been presented in several studies (Wild et al., 2013, 2015; Ma et al., 2015; Bartok et al., 2017). Figure 7 illustrates the large spread of the biases in downward shortwave radiation fluxes simulated by more than 40 CMIP5 models when compared to an average of over 760 sites from
GEBA, covering almost $40 \mathrm{~W} \mathrm{~m}^{-2}$, and documents the overestimation of these fluxes in many of the models.

Also the nonradiative surface energy balance data contained in GEBA have been used for the evaluation of the model climatologies. For example, the surface albedo measurements have been used to assess the simulation of snow albedo in a global climate model (Roesch et al., 1999), and the sensible and latent heat flux data in GEBA have been instrumental in assessing these fluxes in climate models (Wild et al., 1996; Sheppard and Wild, 2002).

Apart from the assessment of the simulated climatological mean fields, a number of studies also used GEBA data to assess the climate model-simulated trends, particularly in the shortwave radiation in the context of the dimming and brightening phenomenon. These studies show that climate models typically do not fully reproduce the strong multidecadal variations seen in the GEBA data (Ruckstuhl and Norris, 2009; Wild and Schmucki, 2011; Zubler et al., 2011; Allen et al., 2013; Bartok et al., 2017). The inadequate representation of decadal changes in aerosols has been suggested as a potential cause for the lack of trends in the simulated surface downward shortwave radiation fields. In contrast, Nabat et al. (2014) were able to adequately reproduce the brightening trends at the GEBA sites over Europe with a regional climate model and a newly compiled dataset on the historic aerosol evolution. While this regional climate model took into account the direct, semi-direct, and first indirect aerosol effects, the simulated brightening was dominated by the direct effect. Folini and Wild (2015) showed that the climate model ECHAM5-HAM with sophisticated treatment of interactive aerosols and emissions from the Japanese National Institute for Environmental Studies (NIES) overall reproduced the magnitude of the recorded trends in China as given in GEBA. GEBA data have been used to assess not only the trends in (total) surface downward shortwave radiation but also of its direct and diffuse components (Mercado et al., 2009).

GEBA data have further extensively served as ground truth for surface radiative fluxes derived from satellites and reanalyses. The earliest investigations that used GEBA data to assess satellite-derived surface fluxes were made by Whitlock et al. (1995), Rossow and Zhang (1995), and Li et al. (1995b). Hatzianastassiou et al. (2005), based on their global satellite-derived surface radiation product validated against GEBA data, provided additional evidence for a lower downward shortwave radiation than commonly assumed, in line with the findings of the GEBA-based global energy balance studies mentioned above. A detailed assessment of their radiation scheme compared to GEBA data over the Mediterranean area was performed by Papadimas et al. (2012) and Pyrina et al. (2015). Hatzianastassiou et al. (2012) further noted that the trends in their surface shortwave radiation product are in reasonable agreement with the GEBA records. An assessment of the Global Energy and Water Cycle Experiment (GEWEX) surface radiation budget (SRB) product 
with GEBA data can be found in Hinkelman et al. (2009) and Zhang et al. (2009). The most recent assessment of surface downward shortwave radiation as provided by four different global satellite products based on GEBA data is documented in Zhang et al. (2015). Over the region covered by the geostationary Meteosat disk, the surface radiative flux products of the Satellite Application Facility on Climate Monitoring (CM-SAF) were extensively validated against GEBA observations (Krahenmann et al., 2013; Sanchez-Lorenzo et al., 2013, 2017; Muller et al., 2015; Alexandri et al., 2017). These studies have also assessed the temporal stability of the satellite-derived surface shortwave radiation against GEBA records, especially over Europe. A comparison of trends of a composite of 47 European GEBA time series with the corresponding composite of the satellite-derived time series from CM-SAF is shown in Fig. 8 (adapted from Sanchez-Lorenzo et al., 2017).

The earliest assessment of reanalysis fluxes using GEBA data is documented in Wild et al. (1998a), while the most upto-date assessment of six recent reanalyses was performed by Zhang et al. (2016). Similarly to climate models, reanalyses were shown to have difficulties in representing the multidecadal variations in surface shortwave radiation seen in the GEBA data (Wild and Schmucki, 2011). The quality of reanalysis-calculated surface radiative fluxes has also been assessed with GEBA data to check their suitability as input data in a global hydrological modeling framework (Müller Schmied et al., 2016).

In summary, GEBA continues to play a major role in the assessment of surface energy fluxes in climate models, satellite-derived products, and reanalyses. Overall, in many satellite-derived and reanalysis products the comparisons with GEBA data revealed a tendency to overestimate the absolute magnitude and underestimate the trends in surface shortwave radiation compared to the ground-based observations. This has been partially related to the use of inadequate representations of aerosols and a lack in their temporal variation.

\subsection{Constraining radiative forcings}

GEBA data have also been used in attempts to constrain historic radiative forcings, particularly from aerosols, and thereby contributed to the estimation of the climate sensitivity. Improved knowledge of the evolution of aerosol forcing since preindustrial times, combined with the observed global warming and estimated greenhouse gas forcing over this period can provide better constraints of the Earth's climate sensitivity. Storelvmo et al. (2016) used the GEBA data as indicators of the historic evolution of the aerosols, which lead to an estimation of a comparatively high transient climate sensitivity at $2.0 \pm 0.8 \mathrm{~K}$ entirely based on observational records, using a statistical approach usually applied to economic time series. The transient climate sensitivity refers to the global mean warming at the time of a doubling of the $\mathrm{CO}_{2}$ concentration.

Cherian et al. (2014) noted that the brightening trend over Europe in several climate models scales well with the regional and global mean effective forcing by anthropogenic aerosols (present day minus preindustrial). Using the observed brightening trend from European GEBA sites as constraint, this enabled the derivation of a global mean total aerosol effective forcing of about $-1.30 \mathrm{~W} \mathrm{~m}^{-2}$.

These studies rely on the assumption that the decadal changes seen in the shortwave GEBA records are predominately induced by direct and indirect aerosol effects.

\subsection{Implications for climate change and applied studies}

Potential implications of the variations in surface radiation as discovered in the GEBA data for different aspects of climate change have been investigated in numerous studies. These include for example their implications for evaporation changes (Wang et al., 2010), for changes in the intensity of the global water cycle (Wild, 2012), for global warming and diurnal temperature range (Wild et al., 2007; Makowski et al., 2009; Wang and Dickinson, 2013a), for changes in isoprene emissions (Stavrakou et al., 2014), and for glacier melt (Ohmura et al., 2007; Huss et al., 2009). Further, GEBA data were used for the assessment of the worldwide variation in diffuse and direct shortwave radiation of relevance for biosphere growth, agricultural production, and tree-ring density (Mercado et al., 2009; Wild et al., 2012; Stine and Huybers, 2014).

On a more applied level, GEBA provides data for the assessment of the resources available for solar power production (Müller et al., 2014) and serves as a database for the software package Meteonorm developed by the company Meteotest, which delivers worldwide information on various aspects of shortwave irradiances for applications in the area of photovoltaic and solar thermal power production as well as building simulations.

\section{Data availability}

Data described in this work are available through the web interface of GEBA at http://www.geba.ethz.ch and are secured at https://doi.org/10.1594/PANGAEA.873078 (Wild et al., 2017).

\section{Summary}

The Global Energy Balance Archive (GEBA), with its variety of surface energy balance parameters and long-term historical records, contains a unique data collection of worldwide measured surface energy fluxes on a monthly basis to serve the scientific community as well as the interested public. GEBA allows the central and uniform storage of the vast number of energy flux measurements from heterogeneous sources that have been performed worldwide over the 


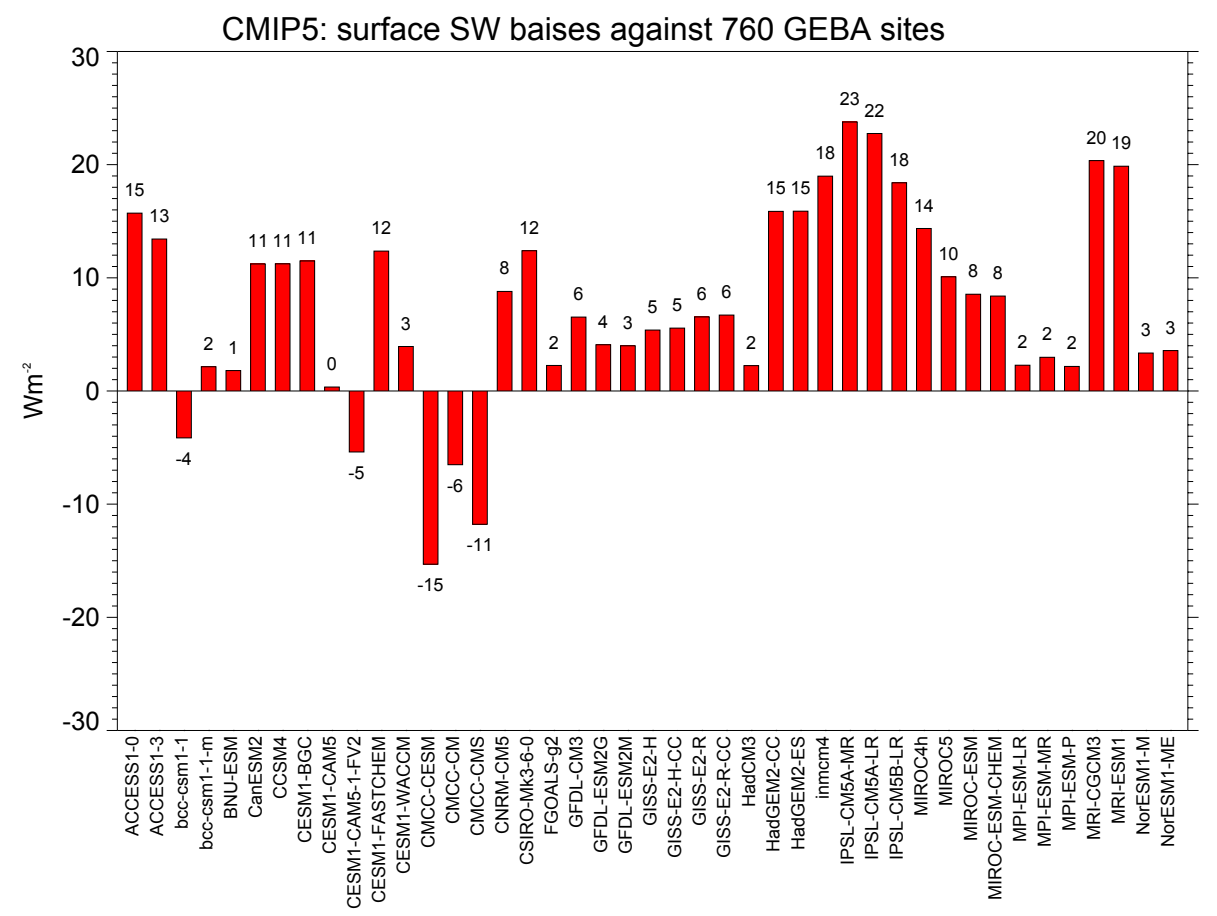

Figure 7. Average biases (model - GEBA observations) in surface downward shortwave radiation (W $\mathrm{m}^{-2}$ ) at Earth's surface calculated in 43 different CMIP5 climate models averaged over 760 sites from GEBA. Adapted from Wild et al., 2015.

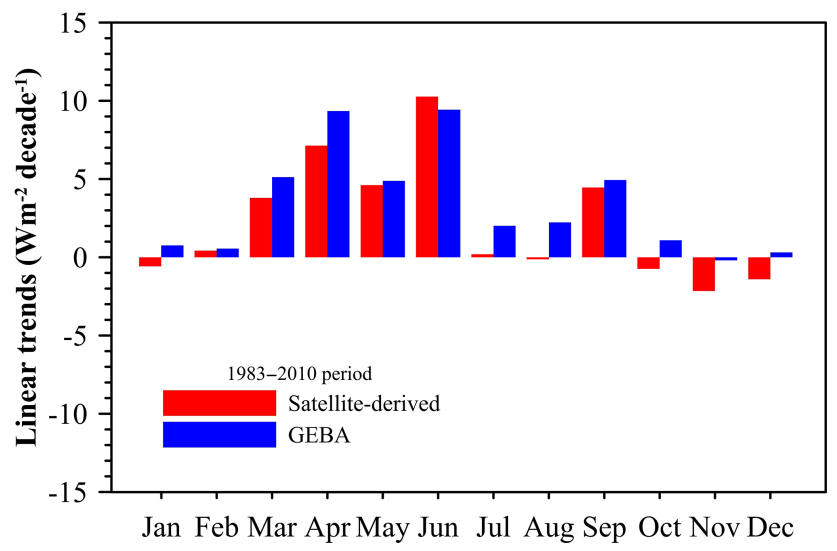

Figure 8. Linear trends in the mean monthly time series of downward shortwave radiation obtained as a composite from 47 GEBA station records and collocated satellite-derived records from CMSAF over Europe over the period 1983-2010. Units in watts per square meter per decade (adapted from Sanchez-Lorenzo et al., 2017).

past decades by a multitude of organizations and individuals, such as under the auspices of national meteorological services, agricultural or environmental agencies, or during expeditions and field campaigns. This paper describes GEBA version 2017 and the updates that this data archive has undergone since its last documentation in the 1990s in terms of its data content, its worldwide access through a newly de- signed web interface, and its new internet address. It further highlights some of the research that has been made based on GEBA. Namely, GEBA has played a key role in the detection of the phenomenon of global dimming and brightening; the quantification of the Earth's surface energy budget and atmospheric absorption; the detection of biases in surface energy fluxes from climate models, reanalyses, and satellite-derived products; the determination of the observation-based transient climate sensitivity and aerosol radiative forcing; and assessments of solar resources for solar power production. It is expected that GEBA will continue to serve as a key information source on instrumentally measured surface energy fluxes in support of the abovementioned and novel research directions in the future.

Competing interests. The authors declare that they have no conflict of intere

Acknowledgements. We are indebted to the IT services at ETH Zurich for their technical support of the GEBA Oracle database and related issues over many years, particularly to Mahan Satari, Bengt Giger, Swen Vermeul, Benno Luthiger, Peter Bircher, and Matteo Corti for their hands-on work on the GEBA database, web interface, and user administration tool. Barbara Trüssel, Stefanos Mystakidis, Pavle Arsenovic, and Mijung Song are acknowledged for their work on data acquisition for GEBA. Thanks also to Hans-Heini Vogel and Urs Beyerle for their support of the transition 
of the GEBA web interface into the new web content management system AEM. A special thank you goes to Hans Gilgen for his efforts to design and manage the GEBA database over many years. We are grateful to Rainer Sieger for his unbureaucratic inclusion of the data in PANGAEA. Barbara Schär designed the energy balance diagram shown in Fig. 4. Arturo Sanchez-Lorenzo was supported by a postdoctoral fellowship JCI-2012-12508 and project CGL201455976-R financed by the Spanish Ministry of Economy and Competitiveness. Thanks very much also to the Editor Gert KönigLanglo and the two reviewers Jörg Trentmann and Joseph Michalsky for their careful assessment of our paper and helpful comments.

We also gratefully acknowledge the many observers out in the field who make all the precious measurements that GEBA relies on and individuals and institutions who make their data available for GEBA.

Edited by: Gert König-Langlo

Reviewed by: Jörg Trentmann and Joseph Michalsky

\section{References}

Alexandri, G., Georgoulias, A. K., Meleti, C., Balis, D., Kourtidis, K. A., Sanchez-Lorenzo, A., Trentmann, J., and Zanis, P.: A high resolution satellite view of surface solar radiation over the climatically sensitive region of Eastern Mediterranean, Atmos. Res., 188, 107-121, https://doi.org/10.1016/j.atmosres.2016.12.015, 2017.

Allen, R. J., Norris, J. R., and Wild, M.: Evaluation of multidecadal variability in CMIP5 surface solar radiation and inferred underestimation of aerosol direct effects over Europe, China, Japan, and India, J. Geophys. Res.-Atmos., 118, 6311-6336, https://doi.org/10.1002/Jgrd.50426, 2013.

Alpert, P., Kishcha, P., Kaufman, Y. J., and Schwarzbard, R.: Global dimming or local dimming?: Effect of urbanization on sunlight availability, Geophys. Res. Lett., 32, L17802, https://doi.org/10.1029/2005g1023320, 2005.

Augustine, J. A., DeLuisi, J. J., and Long, C. N.: SURFRAD - A national surface radiation budget network for atmospheric research, Bull. Am. Meteorol. Soc., 81, 2341-2357, 2000.

Bartok, B., Wild, M., Folini, D., Lüthi, D., Kotlarski, S., Schär, C., Vautard, R., Jerez, S., and Zoltán, I.: Projected changes in surface solar radiation in CMIP5 global climate models and in EURO-CORDEX regional climate models for Europe, Clim. Dyn., https://doi.org/10.1007/s00382-016-3471-2, 2017.

Cherian, R., Quaas, J., Salzmann, M., and Wild, M.: Pollution trends over Europe constrain global aerosol forcing as simulated by climate models, Geophys. Res. Lett., 41, 2176-2181, https://doi.org/10.1002/2013gl058715, 2014.

Chiacchio, M. and Wild, M.: Influence of NAO and clouds on long-term seasonal variations of surface solar radiation in Europe, J. Geophys. Res.-Atmos., 115, D00d22, https://doi.org/10.1029/2009jd012182, 2010.

Folini, D. and Wild, M.: The effect of aerosols and sea surface temperature on China's climate in the late twentieth century from ensembles of global climate simulations, J. Geophys. Res., 120, 2261-2279, https://doi.org/10.1002/2014JD022851, 2015.

Franssen, H. J. H., Stockli, R., Lehner, I., Rotenberg, E., and Seneviratne, S. I.: Energy balance closure of eddy-covariance data: A multisite analysis for European FLUXNET stations, Agr. Forest Meteorol., 150, 1553-1567, https://doi.org/10.1016/j.agrformet.2010.08.005, 2010.

Gilgen, $H$. and Ohmura, A.: The Global Energy Balance Archive, Bull. Am. Meteorol. Soc., $\quad 80, \quad 831-850, \quad$ https://doi.org/10.1175/1520 0477(1999)080<0831:Tgeba>2.0.Co;2, 1999.

Gilgen, H., Wild, M., and Ohmura, A.: Global Energy Balance Archive GEBA, World Climate Program - Water Project A7, Report 3: The GEBA Version 1997 Database, Zurich, 105 pp., 1997.

Gilgen, H., Wild, M., and Ohmura, A.: Means and trends of shortwave irradiance at the surface estimated from global energy balance archive data, J. Climate, 11, 2042-2061, 1998.

Hakuba, M. Z., Folini, D., Sanchez-Lorenzo, A., and Wild, M.: Spatial representativeness of ground-based solar radiation measurements, J. Geophys. Res., 118, 8585-8597, https://doi.org/10.1002/jgrd.50673, 2013.

Hakuba, M. Z., Folini, D., Sanchez-Lorenzo, A., and Wild, M.: Spatial representativeness of ground-based solar radiation measurements-Extension to the full Meteosat disk, J. Geophys. Res., 119, 11760-11771, https://doi.org/10.1002/2014jd021946, 2014a.

Hakuba, M. Z., Folini, D., Schaepman-Strub, G., and Wild, M.: Solar Absorption over Europe from collocated surface and satellite observations, J. Geophys. Res., 119, 3420-3437, https://doi.org/10.1002/2013JD021421, 2014b.

Hakuba, M. Z., Folini, D., and Wild, M.: On the Zonal NearConstancy of Fractional Solar Absorption in the Atmosphere, J. Climate, 29, 3423-3440, https://doi.org/10.1175/Jcli-D-150277.1, 2016.

Hatzianastassiou, N., Matsoukas, C., Fotiadi, A., Pavlakis, K. G., Drakakis, E., Hatzidimitriou, D., and Vardavas, I.: Global distribution of Earth's surface shortwave radiation budget, Atmos. Chem. Phys., 5, 2847-2867, https://doi.org/10.5194/acp-5-28472005, 2005.

Hatzianastassiou, N., Papadimas, C. D., Matsoukas, C., Pavlakis, K., Fotiadi, A., Wild, M., and Vardavas, I.: Recent regional surface solar radiation dimming and brightening patterns: inter-hemispherical asymmetry and a dimming in the Southern Hemisphere, Atmos. Sci. Lett., 13, 43-48, https://doi.org/10.1002/asl.361, 2012.

Hinkelman, L. M., Stackhouse, P. W., Wielicki, B. A., Zhang, T. P., and Wilson, S. R.: Surface insolation trends from satellite and ground measurements: Comparisons and challenges, J. Geophys. Res.-Atmos., 114, D00d20, https://doi.org/10.1029/2008jd011004, 2009.

Huss, M., Funk, M., and Ohmura, A.: Strong Alpine glacier melt in the 1940s due to enhanced solar radiation, Geophys. Res. Lett., 36, L23501, https://doi.org/10.1029/2009GL040789, 2009.

Imamovic, A., Tanaka, K., Folini, D., and Wild, M.: Global dimming and urbanization: did stronger negative SSR trends collocate with regions of population growth?, Atmos. Chem. Phys., 16, 2719-2725, https://doi.org/10.5194/acp-16-27192016, 2016.

Krahenmann, S., Obregon, A., Muller, R., Trentmann, J., and Ahrens, B.: A Satellite-Based Surface Radiation Climatology Derived by Combining Climate Data Records and Near-Real-Time Data, Remote Sens.-Basel, 5, 4693-4718, https://doi.org/10.3390/rs5094693, 2013. 
Li, Z. Q., Barker, H. W., and Moreau, L.: The Variable Effect of Clouds on Atmospheric Absorption of Solar-Radiation, Nature, 376, 486-490, 1995a.

Li, Z. Q., Whitlock, C. H., and Charlock, T. P.: Assessment of the Global Monthly Mean Surface Insolation Estimated from Satellite Measurements Using Global Energy-Balance Archive Data, J. Climate, 8, 315-328, https://doi.org/10.1175/15200442(1995)008<0315:Aotgmm>2.0.Co;2, 1995b.

Liepert, B. G.: Observed reductions of surface solar radiation at sites in the United States and worldwide from 1961 to 1990, Geophys. Res. Lett., 29, 1421, https://doi.org/10.1029/2002g1014910, 2002.

Ma, Q., Wang, K. C., and Wild, M.: Impact of geolocations of validation data on the evaluation of surface incident shortwave radiation from Earth System Models, J. Geophys. Res.-Atmos., 120, 6825-6844, https://doi.org/10.1002/2014jd022572, 2015.

Makowski, K., Jaeger, E. B., Chiacchio, M., Wild, M., Ewen, T., and Ohmura, A.: On the relationship between diurnal temperature range and surface solar radiation in Europe, J. Geophys. Res.Atmos., 114, D00d07, https://doi.org/10.1029/2008jd011104, 2009.

Marty, C., Philipona, R., Delamere, J., Dutton, E. G., Michalsky, J., Stamnes, K., Storvold, R., Stoffel, T., Clough, S. A., and Mlawer, E. J.: Downward longwave irradiance uncertainty under arctic atmospheres: Measurements and modeling, J. Geophys. Res.Atmos., 108, 4358, https://doi.org/10.1029/2002jd002937, 2003.

Mercado, L. M., Bellouin, N., Sitch, S., Boucher, O., Huntingford, C., Wild, M., and Cox, P. M.: Impact of changes in diffuse radiation on the global land carbon sink, Nature, 458, 1014-1018, https://doi.org/10.1038/Nature07949, 2009.

Michalsky, J., Dutton, E., Rubes, M., Nelson, D., Stoffel, T., Wesley, M., Splitt, M., and DeLuisi, J.: Optimal measurement of surface shortwave irradiance using current instrumentation, J. Atmos. Ocean Tech., 16, 55-69, 1999.

Michalsky, J. J., Gueymard, C., Kiedron, P., McArthur, L. J. B., Philipona, R., and Stoffel, T.: A proposed working standard for the measurement of diffuse horizontal shortwave irradiance, J. Geophys. Res.-Atmos., 112, D16112, https://doi.org/10.1029/2007jd008651, 2007.

Müller, B., Wild, M., Driesse, A., and Behrens, K.: Rethinking solar resource assessments in the context of global dimming and brightening, Solar Energy, 99, 272-282, 2014.

Müller Schmied, H. M., Muller, R., Sanchez-Lorenzo, A., Ahrens, B., and Wild, M.: Evaluation of Radiation Components in a Global Freshwater Model with Station-Based Observations, Water-Sui., 8, 450, https://doi.org/10.3390/w8100450, 2016.

Muller, R., Pfeifroth, U., Traeger-Chatterjee, C., Trentmann, J., and Cremer, R.: Digging the METEOSAT Treasure-3 Decades of Solar Surface Radiation, Remote Sens.-Basel, 7, 8067-8101, https://doi.org/10.3390/rs70608067, 2015.

Nabat, P., Somot, S., Mallet, M., Sanchez-Lorenzo, A., and Wild, M.: Contribution of anthropogenic sulfate aerosols to the changing Euro-Mediterranean climate since 1980, Geophys. Res. Lett., 41, 5605-5611, https://doi.org/10.1002/2014g1060798, 2014.

Norris, J. R. and Wild, M.: Trends in aerosol radiative effects over Europe inferred from observed cloud cover, solar "dimming" and solar "brightening", J. Geophys. Res.-Atmos., 112, D08214, https://doi.org/10.1029/2006jd007794, 2007.
Norris, J. R. and Wild, M.: Trends in aerosol radiative effects over China and Japan inferred from observed cloud cover, solar "dimming," and solar "brightening", J. Geophys. Res.-Atmos., 114, D00d15, https://doi.org/10.1029/2008jd011378, 2009.

Ohmura, A.: Observed long-term variations of solar irradiance at the earth's surface, Space Science Reviews, 125, 111-128, https://doi.org/10.1007/s11214-006-9050-9, 2006.

Ohmura, A.: Observed decadal variations in surface solar radiation and their causes, J. Geophys. Res.-Atmos., 114, D00d05, https://doi.org/10.1029/2008jd011290, 2009.

Ohmura, A. and Gilgen, H.: Global Energy Balance Archive GEBA, World Climate Program - Water Project A7, Report 2: The GEBA Database: Interactive Applications, Retrieving Data, Zurich, 66 pp., 1991.

Ohmura, A. and Gilgen, H.: Reevaluation of the global energy balance, in: Interactions between Global Climate Subsystems - the Legacy of Hann, edited by: McBean, G. A. and Hantel, M., Geophysical Monograph Series, Amer Geophysical Union, Washington, 93-110, 1993.

Ohmura, A. and Lang, H.: Secular variations of global radiation in Europe, IRS '88: Current Problems in Atmospheric Radiation, Lille, France, 1989.

Ohmura, A. and Raschke, E.: Energy Budget at the Earth's Surface., in: Observed Global Climate. Landolt-Börnstein: Numerical Data and Functional Relationships in Science and Technology - New Series, edited by: Hantel, M., Springer Berlin, Heidelberg, New York, 2005.

Ohmura, A., Gilgen, H., and Wild, M.: Global Energy Balance Archive GEBA, World Climate Program - Water Project A7, Zurich, 62 pp., 1989.

Ohmura, A., Dutton, E. G., Forgan, B., Frohlich, C., Gilgen, H., Hegner, H., Heimo, A., König-Langlo, G., McArthur, B., Muller, G., Philipona, R., Pinker, R., Whitlock, C. H., Dehne, K., and Wild, M.: Baseline Surface Radiation Network (BSRN/WCRP): New precision radiometry for climate research, Bull. Am. Meteorol. Soc., 79, 2115-2136, 1998.

Ohmura, A., Bauder, A., Muller, H., and Kappenberger, G.: Longterm change of mass balance and the role of radiation, Ann. Glaciol., 46, 367-374, 2007.

Papadimas, C. D., Hatzianastassiou, N., Matsoukas, C., Kanakidou, M., Mihalopoulos, N., and Vardavas, I.: The direct effect of aerosols on solar radiation over the broader Mediterranean basin, Atmos. Chem. Phys., 12, 7165-7185, https://doi.org/10.5194/acp-12-7165-2012, 2012.

Philipona, R., Dutton, E. G., Stoffel, T., Michalsky, J., Reda, I., Stifter, A., Wendling, P., Wood, N., Clough, S. A., Mlawer, E. J., Anderson, G., Revercomb, H. E., and Shippert, T. R.: Atmospheric longwave irradiance uncertainty: Pyrgeometers compared to an absolute sky-scanning radiometer, atmospheric emitted radiance interferometer, and radiative transfer model calculations, J. Geophys. Res.-Atmos., 106, 28129-28141, 2001.

Pyrina, M., Hatzianastassiou, N., Matsoukas, C., Fotiadi, A., Papadimas, C. D., Pavlakis, K. G., and Vardavas, I.: Cloud effects on the solar and thermal radiation budgets of the Mediterranean basin, Atmos. Res., 152, 14-28, https://doi.org/10.1016/j.atmosres.2013.11.009, 2015.

Roesch, A., Gilgen, H., Wild, M., and Ohmura, A.: Assessment of GCM simulated snow albedo using direct observations, Clim. Dynam., 15, 405-418, 1999. 
Rossow, W. B. and Zhang, Y. C.: Calculation of Surface and Top of Atmosphere Radiative Fluxes from Physical Quantities Based on Isccp Data Sets .2. Validation and First Results, J. Geophys. Res., 100, 1167-1197, 1995.

Ruckstuhl, C. and Norris, J. R.: How do aerosol histories affect solar "dimming" and "brightening" over Europe?: IPCC-AR4 models versus observations, J. Geophys. Res.-Atmos., 114, D00d04, https://doi.org/10.1029/2008jd011066, 2009.

Sanchez-Lorenzo, A., Wild, M., and Trentmann, J.: Validation and stability assessment of the monthly mean CM SAF surface solar radiation dataset over Europe against a homogenized surface dataset (1983-2005), Remote Sens. Environ., 134, 355-366, https://doi.org/10.1016/J.Rse.2013.03.012, 2013.

Sanchez-Lorenzo, A., Wild, M., Brunetti, M., Guijarro, J. A., Hakuba, M. Z., Calbo, J., Mystakidis, S., and Bartok, B.: Reassessment and update of long-term trends in downward surface shortwave radiation over Europe (1939-2012), J. Geophys. Res.Atmos., 120, 9555-9569, https://doi.org/10.1002/2015jd023321, 2015.

Sanchez-Lorenzo, A., Enriquez-Alonso, A., Wild, M., Trentmann, J., Vicente-Serrano, S., Sanchez-Romero, A., Posselt, R., and Hakuba, M. Z.: Trends in downward surface solar radiation from satellites and ground observations over Europe during 1983-2010, Remote Sens. Environ., 189, 108-117, https://doi.org/10.1016/j.rse.2016.11.018, 2017.

Sheppard, R. and Wild, M.: Simulated turbulent fluxes over land from general circulation models and reanalyses compared with observations, Int. J. Climatol., 22, 1235-1247, https://doi.org/10.1002/joc.792, 2002.

Stanhill, G. and Cohen, S.: Global dimming: a review of the evidence for a widespread and significant reduction in global radiation with discussion of its probable causes and possible agricultural consequences, Agr. Forest Meteorol., 107, 255-278, 2001.

Stavrakou, T., Müller, J.-F., Bauwens, M., De Smedt, I., Van Roozendael, M., Guenther, A., Wild, M., and Xia, X.: Isoprene emissions over Asia 1979-2012: impact of climate and land-use changes, Atmos. Chem. Phys., 14, 4587-4605, https://doi.org/10.5194/acp-14-4587-2014, 2014.

Stine, A. R. and Huybers, P.: Arctic tree rings as recorders of variations in light availability, Nat. Commun, 5, 3836, https://doi.org/10.1038/Ncomms4836, 2014.

Stokes, G. M. and Schwartz, S. E.: The Atmospheric Radiation Measurement (Arm) Program - Programmatic Background and Design of the Cloud and Radiation Test-Bed, Bull. Am. Meteorol. Soc., 75, 1201-1221, 1994.

Storelvmo, T., Leirvik, T., Lohmann, U., Phillips, P. C. B., and Wild, M.: Disentangling greenhouse warming and aerosol cooling to reveal Earth's climate sensitivity, Nature Geosci., 9, 289, https://doi.org/10.1038/Ngeo2670, 2016.

Wang, K. C. and Dickinson, R. E.: Contribution of solar radiation to decadal temperature variability over land, P. Natl. Acad. Sci. USA, 110, 14877-14882, https://doi.org/10.1073/Pnas.1311433110, 2013a.

Wang, K. C. and Dickinson, R. E.: Global atmospheric downward longwave radiation at the surface from ground-based observations, satellite retrievals, and reanalyses, Rev. Geophys., 51, 150185, https://doi.org/10.1002/Rog.20009, 2013b.

Wang, K. C., Dickinson, R. E., Wild, M., and Liang, S. L.: Evidence for decadal variation in global terrestrial evapotranspiration be- tween 1982 and 2002: 2. Results, J. Geophys. Res.-Atmos., 115, D20113, https://doi.org/10.1029/2010jd013847, 2010.

Wang, K. C., Ma, Q., Wang, X. Y., and Wild, M.: Urban impacts on mean and trend of surface incident solar radiation, Geophys. Res. Lett., 41, 4664-4668, https://doi.org/10.1002/2014g1060201, 2014.

Whitlock, C. H., Charlock, T. P., Staylor, W. F., Pinker, R. T., Laszlo, I., Ohmura, A., Gilgen, H., Konzelman, T., Dipasquale, R. C., Moats, C. D., Lecroy, S. R., and Ritchey, N. A.: First Global Wcrp Shortwave Surface Radiation Budget Dataset, Bull. Am. Meteorol. Soc., 76, 905-922, https://doi.org/10.1175/15200477(1995)076<0905:Fgwssr>2.0.Co;2, 1995.

Wild, M.: Absorption of solar energy in cloudless and cloudy atmospheres over Germany and in GCMs, Geophys. Res. Lett., 27, 959-962, 2000.

Wild, M.: Short-wave and long-wave surface radiation budgets in GCMs: a review based on the IPCC-AR4/CMIP3 models, Tellus A, 60, 932-945, https://doi.org/10.1111/J.16000870.2008.00342.X, 2008.

Wild, M.: Global dimming and brightening: A review, J. Geophys. Res.-Atmos., 114, D00d16, https://doi.org/10.1029/2008jd011470, 2009.

Wild, M.: Enlightening Global Dimming and Brightening, Bull. Am. Meteorol. Soc., 93, 27-37, https://doi.org/10.1175/Bams-D11-00074.1, 2012.

Wild, M.: Decadal changes in radiative fluxes at land and ocean surfaces and their relevance for global warming, Wires Clim. Change, 7, 91-107, https://doi.org/10.1002/wcc.372, 2016.

Wild, M. and Schmucki, E.: Assessment of global dimming and brightening in IPCC-AR4/CMIP3 models and ERA40, Clim. Dynam., 37, 1671-1688, https://doi.org/10.1007/S00382-0100939-3, 2011.

Wild, M., Ohmura, A., Gilgen, H., and Roeckner, E.: Validation of General-Circulation Model Radiative Fluxes Using Surface Observations, J. Climate, 8, 1309-1324, 1995.

Wild, M., Dumenil, L., and Schulz, J. P.: Regional climate simulation with a high resolution GCM: Surface hydrology, Clim. Dynam., 12, 755-774, 1996.

Wild, M., Ohmura, A., Gilgen, H., and Morcrette, J. J.: The distribution of solar energy at the Earth's surface as calculated in the ECMWF Re-Analysis, Geophys. Res. Lett., 25, 4373-4376, https://doi.org/10.1029/1998g1900175, 1998a.

Wild, M., Ohmura, A., Gilgen, H., Roeckner, E., Giorgetta, M., and Morcrette, J. J.: The disposition of radiative energy in the global climate system: GCM-calculated versus observational estimates, Clim. Dynam., 14, 853-869, 1998b.

Wild, M., Gilgen, H., Roesch, A., Ohmura, A., Long, C. N., Dutton, E. G., Forgan, B., Kallis, A., Russak, V., and Tsvetkov, A.: From dimming to brightening: Decadal changes in solar radiation at Earth's surface, Science, 308, 847-850, https://doi.org/10.1126/science.1103215, 2005.

Wild, M., Ohmura, A., and Makowski, K.: Impact of global dimming and brightening on global warming, Geophys. Res. Lett., 34, L04702, https://doi.org/10.1029/2006g1028031, 2007.

Wild, M., Roesch, A., and Ammann, C.: Global dimming and brightening - evidence and agricultural implications., $\mathrm{CAB}$ Reviews, 7, 1-7, https://doi.org/10.1079/PAVSNNR20127003, 2012. 
Wild, M., Folini, D., Schar, C., Loeb, N., Dutton, E. G., and König-Langlo, G.: The global energy balance from a surface perspective, Clim. Dynam., 40, 3107-3134, https://doi.org/10.1007/S00382-012-1569-8, 2013.

Wild, M., Folini, D., Hakuba, M. Z., Schar, C., Seneviratne, S. I., Kato, S., Rutan, D., Ammann, C., Wood, E. F., and KonigLanglo, G.: The energy balance over land and oceans: an assessment based on direct observations and CMIP5 climate models, Clim. Dynam., 44, 3393-3429, https://doi.org/10.1007/s00382014-2430-z, 2015.

Wild, M., Ohmura, A., Schär, C., Müller, G., Folini, D., Schwarz, M., Zyta Hakub, M., and Sanchez-Lorenzo, A.: Supplement to "The Global Energy Balance Archive (GEBA): A database for worldwide measured surface energy fluxes", available at: https://doi.org/10.1594/PANGAEA.873078, 2017.

Zhang, T. P., Stackhouse, P. W., Gupta, S. K., Cox, S. J., and Mikovitz, J. C.: Validation and Analysis of the Release 3.0 of the NASA GEWEX Surface Radiation Budget Dataset, Current Problems in Atmospheric Radiation (Irs 2008), 1100, 597-600, 2009.
Zhang, X. T., Liang, S. L., Wild, M., and Jiang, B.: Analysis of surface incident shortwave radiation from four satellite products, Remote Sens. Environ., 165, 186-202, https://doi.org/10.1016/j.rse2015.05.015, 2015.

Zhang, X. T., Liang, S. L., Wang, G. X., Yao, Y. J., Jiang, B., and Cheng, J.: Evaluation of the Reanalysis Surface Incident Shortwave Radiation Products from NCEP, ECMWF, GSFC, and JMA Using Satellite and Surface Observations, Remote Sens.-Basel, 8, 225, https://doi.org/10.3390/rs8030225, 2016.

Zubler, E. M., Folini, D., Lohmann, U., Luthi, D., Schar, C., and Wild, M.: Simulation of dimming and brightening in Europe from 1958 to 2001 using a regional climate model, J. Geophys. Res.-Atmos., 116, D18205, https://doi.org/10.1029/2010jd015396, 2011. 